\title{
Effects of Language on Visual Perception
}

\author{
Gary Lupyan ${ }^{1 \mathrm{a}}$, Rasha Abdel Rahman ${ }^{\mathrm{b}}$, Lera Boroditsky ${ }^{\mathrm{c}}$, Andy Clark $^{\mathrm{d}}$ \\ ${ }^{a}$ University of Wisconsin-Madison \\ ${ }^{b}$ Humboldt-Universität zu Berlin \\ ${ }^{c}$ University of California San Diego \\ ${ }^{d}$ University of Sussex
}

\begin{abstract}
Does language change what we perceive? Does speaking different languages cause us to perceive things differently? We review the behavioral and electrophysiological evidence for the influence of language on perception, with an emphasis on the visual modality. Effects of language on perception can be observed both in higher-level processes such as recognition, and in lower-level processes such as discrimination and detection. A consistent finding is that language causes us to perceive in a more categorical way. Rather than being fringe or exotic, as they are sometimes portrayed, we discuss how effects of language on perception naturally arise from the interactive and predictive nature of perception.
\end{abstract}

Keywords: language; perception; vision; categorization; top-down effects; prediction

"Even comparatively simple acts of perception are very much more at the mercy of the social patterns called words than we might suppose." [1].

"No matter how influential language might be, it would seem preposterous to a physiologist that it could reach down into the retina and rewire the ganglion cells" [2].

\footnotetext{
${ }^{1}$ Correspondence: lupyan@wisc.edu
} 


\section{Language as a form of experience that affects perception}

What factors influence how we perceive the world? For example, what makes it possible to recognize the object in Fig. 1a? Or to locate the 'target' in Fig. 1b? Where is the head of the bird in Fig. 1c? Why do we perceive some colors in Fig. 1d as more similar than others? Research on visual perception has sought to answer such questions by focusing largely on the physical properties of the stimuli and their interactions, [e.g. 3-5]. However, it has been long appreciated that what we perceive is determined not only by the physical properties of the current input, but also by our perceptual history. For example, consider how much harder it is to read upside-down text [6] or to match a stranger's vs. a friend's photograph to their actual face [7]. Such effects of prior experience on perception can be observed not only for arguably "higher-level" processes such as recognition, but also for "lower-level" processes such as amodal completion [8], computing shape from motion [9], and computing 3-dimensional structure from object contours [10] and binocular disparity [11]. Although there is continued debate on the "modularity" of some of these processes [3] [cf. 12, 13], there is relative consensus that what we perceive is importantly shaped by prior experience, [e.g. 14]. But what kinds of experiences matter?

A growing number of studies show that perception is affected by language. Most uncontroversially, experience with language affects perception of language. In learning English, we learn to perceive certain speech sounds as being functionally similar. This process of categorization distorts our perception, causing us to perceive physically equidistant sounds as more or less similar depending on our linguistic experience [15, 16]. Such effects do not end at the level of individual speech sounds. Our experience with grouping certain combinations of speech sounds into larger units (such as words) causes us to perceive the same sounds differently, depending on which word they are embedded in [17, 18]. Learning to read has profound impacts on a large part of our visual cortex [e.g. 19]; the consequences can be readily appreciated by comparing the experience of looking at a familiar versus an unfamiliar writing system.

More controversially, experience with language and its in-the-moment use can affect perception of nonlinguistic material. In the next sections we review evidence of how language affects different aspects of perception. We focus on visual perception, not because effects of language on perception are limited to the visual modality, but because this is where most work has con- 
(a)

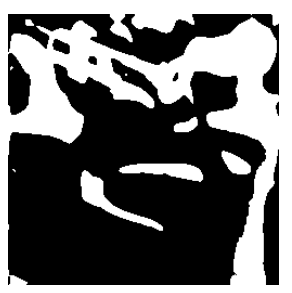

(c)

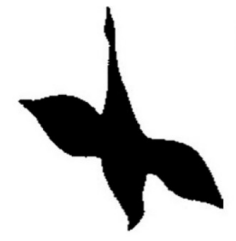

(b)

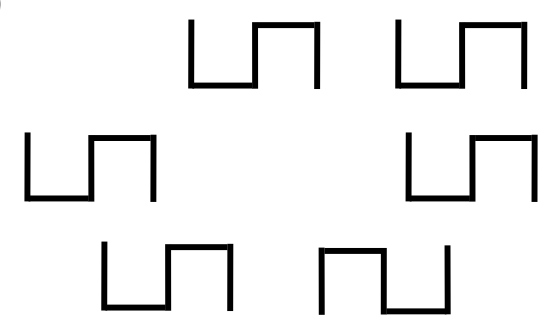

(d) ПППППППППП

Figure 1: Some examples of stimuli used to study influences of language on visual perception. (a) A two-tone "Mooney image" that becomes much easier to recognize after a verbal hint. (b) A sample visual search display. The target (odd-one-out) shape becomes easier to find when informed that the shapes are rotated numbers. (c) The location of this bird's head depends on expectations set up by reading descriptions of motion. (d) Psychophysically equidistant colors that may become perceived more categorically under the influence of the names "green" and "blue". See text for details.

centrated (But see Box 2). We begin by describing two types of linguistic effects on perception: off-line effects in which long-term experience with a specific language affects how people subsequently experience certain perceptual inputs, and on-line effects in which some aspect of language, such as an object's name, interacts with in-the-moment visual processing. We then review empirical evidence of linguistic influences on perception, distinguishing effects of language on (visual) recognition, discrimination, and detection. We discuss whether differences in linguistic experience give rise to differences in perceptual experience and consider how the variety of the findings we review may arise from the workings of a perceptual system that seeks to minimize prediction error [20-22]. 


\section{Effects of language on recognition, discrimination, and detection}

Effects of language on recognition. Seeing a chair and recognizing it as such requires relating the current perceptual input to a previous state (this thing before me is a chair because it looks more like things I've seen previously that are chairs compared to things that are not chairs). To recognize is to categorize [23]. Might the categories we learn as part of learning a language affect visual recognition? Because we are so well-practiced in recognizing conventionally presented images, a productive method of studying recognition involves presenting incomplete or otherwise fragmented images. For example, only about $25 \%$ of people can recognize the object shown in the "Mooney" image in Fig. 1A. That is, given this input, most people's perceptual systems fail to make sense of it. The same input can be made meaningful if we are allowed to glimpse a conventional version of the image of the sort we have more experience recognizing. Glimpsing the conventional image changes not just the ultimate recognition success, but causes measurable changes at various levels of the visual hierarchy [24, 25], for example affecting people's ability to detect image contours, a relatively low-level perceptual task [12].

Could similar increases in recognition be achieved with the aid of language? In a now-classic paper arguing for the cognitively impenetrable nature of visual perception, Pylyshyn argued that "verbal hints [have] little effect on recognizing fragmented figures" [26] such as those in Fig. 1A. Contradicting this assertion, a recent study [13] found that recognition can be substantially increased by simply giving verbal hints. For example, providing people with 15 alternatives as choices increases correct recognition of Fig. 1A to $89 \%$. Recognition can be increased to nearly the same level by providing a superordinate cue such as "musical instrument". One way to think about such effects is that the labels help to form hypotheses against which the incoming visual input can be tested. An otherwise uninterpretable perceptual input becomes interpretable when processed in light of hypotheses generated by language (see the Section Making Sense of the Evidence).

Can language change our recognition of a visual scene, even when the visual scene is unrelated to the linguistic content? In one study [27], people viewed an ambiguous image (Fig. 1C) after they had seen real upward or downward motion or read a linguistic description of physical motion (entirely unrelated to birds). Afterwards, participants were simply asked to draw a worm in the bird's beak. People's recognition of the bird's head was affected similarly by viewing real motion and by reading stories describing physical 
motion.

It may be tempting to interpret some of these effects as effects of language on downstream interpretations of perceptual processes which themselves remain free from linguistic influence [28]. One way of distinguishing processes that are more clearly perceptual from those that may reflect higher-level semantic or downstream decision-making processes is by using event-related brain potentials (ERPs). Some ERPs are associated with the processing of low-level visual properties as lightness and contrast (P1 component, peaking at around $100 \mathrm{~ms}$ [29]) or high-level perception of objects and faces (N1 component, peaking at around $150 \mathrm{~ms})[30,31]$. Other components such as the N400 are better described as tracking more amodal (or multimodal) semantic processing [32, 33]. These studies find that holding perceptual experience constant while varying how much one learns about a novel object - through language - affects early visual processing of objects. Learning an object's name or function decreases subsequent $\mathrm{P} 1$ amplitudes during passive viewing [34, 35]. The early changes in visual processing indexed by these electrophysiological markers are associated not only with changes to visual recognition [36] but also in changes in discrimination and conscious awareness, as the next two sections describe.

Effects of language on discrimination. While recognizing an image requires that it be discriminated from possible alternatives, it is certainly possible to successfully discriminate images without recognizing them. For example, we can discriminate between the letters of a novel alphabet without being able to recognize the letters. We can use discrimination tasks to tell whether effects of language on perception extend beyond recognition.

Many investigations of how language affects discrimination have been done in the domain of color. Indeed, the finding that color names may influence color discrimination is often viewed as a key test of the Whorfian Hypothesis [39-41] even though Whorf never proposed that language should affect color perception. This topic has been extensively reviewed elsewhere [41-45], but we highlight a few findings that show the variety of ways ways that language affects color perception.

What makes color an excellent domain of study is that the physical stimulus is continuous, but we tend to talk about it categorically. Learning color words necessarily requires learning to group colors into categories named by our language - treating different colors that have the same name as more similar than psychophysically equidistant colors named with distinct labels. 
(a)

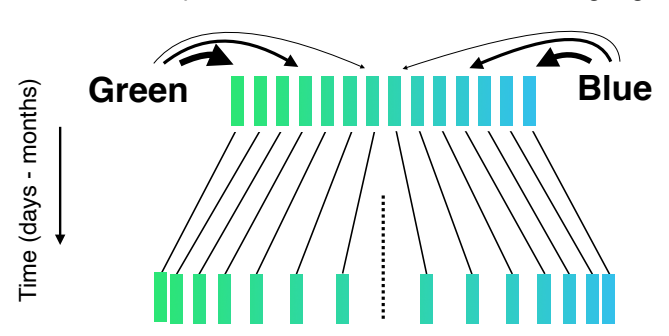

Color representations permanently warped after learning color labels

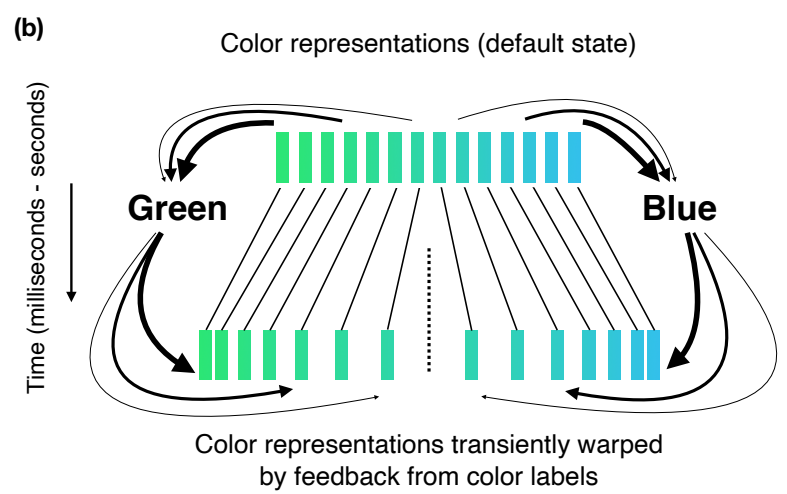

by feedback from color labels

Figure 2: Schematic of (a) off-line and (b) on-line effects of color labels on color representations. (a). Colors that are originally represented as equally discriminable may become gradually warped by the categorization required for comprehending and producing color names. (b) Categorical effects may be produced by a color percept activating a verbal label which then feeds back and warps the color representation into a more categorical form in-the-moment. Note that because the labels "blue" and "green" are more strongly associated with some blues and greens than others (denoted by line thickness), a more categorical representation leads to expansion not only around the category boundary, but also around the middle of the category [see also Fig 2 in 37] leading to improved discrimination of atypical members from slightly more typical ones [38]. On-line effects may be caused by covert labeling (automatic activation of labels by perceptual inputs and further exaggerated by overt labeling such as actively naming a color or reading/hearing a color term.

This in turn may cause us to perceive color in a more categorical way. Adding to the intrigue, some languages have many color words, while others have few or none (See Box 1).

Language has been shown to influence color perception in two main ways, roughly in line with off-line and on-line influences schematized in Fig. 2. First, are studies showing that people speaking different languages show somewhat different patterns of color discrimination. Russian speakers who obligatorily distinguish between light and dark blues in language show a relative advantage in discriminating colors that span the light/dark blue boundary compared to English speakers [46]. Similar differences in discrimination have been found when comparing speakers of other languages that differ in their color naming such as English and Korean [e.g. 47]. Use of EEG has allowed researchers to see that cross-linguistic differences in color discrimination tasks emerge as early as $100 \mathrm{~ms}$. after viewing a color [48 50]. Similar 
effects on early visual processing are observed processing objects that are lexically distinguished in one language, but not another [51].

Second, are studies showing that color discrimination can be altered within an individual by manipulating linguistic factors. Learning new color categories (analogous in some ways to children learning to produce and comprehend color labels) can induce more categorical color perception [52 54$]$ a finding consistent with both off-line and on-line effects of language (Fig. $2 a$ ). At the same time, several lines of evidence show that interfering with labels can reduce or eliminate categorical effects [55] and negate cross-linguistic differences [46]. Conversely, overt use of color labels during the task has been found to exaggerate categorical influences on perception. For example, presenting participants with a color word (e.g., "blue") immediately prior to requiring them to discriminate one color from three others (a simultaneous odd-one-out discrimination task) dramatically improves their ability to distinguish blues from greens while slightly reducing accuracy of distinguishing highly typical blues from slightly less typical blues [38]. Incorporating category typicality (as differential association between an exemplar and its label) into the model makes a further counter-intuitive prediction: as the activation of a category label shifts perceptual representations toward category prototypes, the shift will not only impact colors straddling the category boundary, but also spread to colors around the middle of the category, as schematized in Fig. 2b. Indeed, hearing a color label such as "blue" was found to increase the accuracy with which people distinguished typical blues from less typical blues [38]. Another intriguing effect is that of stimulus order. Imagine seeing a green color swatch $\mathrm{G}_{1}$. Then after a short delay, you are asked to select whether you saw $\mathrm{G}_{1}$ or $\mathrm{G}_{2}$. It turns out that accuracy is substantially better if $\mathrm{G}_{1}$ is the more typical green than if $\mathrm{G}_{2}$ is the more typical green [56, 57]. One explanation is that the category label is activated more strongly by the more typical color and the label then feeds back to warp the representational distance between the two color stimuli enabling more accurate matching [38]. (The effect of presenting the most prototypical stimulus first is predicted to reverse if both $\mathrm{G}_{1}$ and $\mathrm{G}_{2}$ are near the category prototype).

Somewhat more circumstantial evidence for the involvement of language in color perception comes from findings that in color discrimination tasks people show a larger between-category advantage in the right visual field (which projects to the left hemisphere) than in the left visual field [47, 53, 55, 58, 59], that verbal interference selectively affects between-category discrimination in the right visual field [55], and that the lateralization difference is already ob- 
served in early visual processing as measured by EEGs [60]. In related studies using functional neuroimaging, it has been found that color discrimination tasks evoke activity in cortical regions associated with naming (e.g., the left middle and superior temporal gyrus), that this activation is stronger for colors viewed in the right visual field[61], and that discriminating easy to name colors evoked greater activity in "naming" regions compared to discriminating harder-to-name colors [62]. Not everyone agrees that finding categorical perception in the left hemisphere implies that language plays or has played a causal role. One alternative is that the observed lateralization effect may stem from the left hemisphere being more specialized for categorical processing regardless of language [63, 64]. The lateralization effect has also not always replicated [65, 66], suggesting that it may be more fragile than originally thought, a critique that has also been levied against studies showing effects of labels on color memory [c.f. 67, 68] (see Outstanding Questions).

The effects of language on visual discrimination are not limited to colors. Ascribing meaning to simple objects - for example referring to the shapes in Fig. 1B as "rotated numbers" — leads to more efficient visual search [69]. Search can likewise be improved simply by referring to an object by its name. For example, when repeatedly searching for a B among p's, hearing "find the B" shortly before the search display speeds reaction times compared to hearing "find the target" even though the label was uninformative because "B" was always the target [70]. People's visual discrimination of novel "alien" creatures is improved by learning to associate them with dissimilar verbal labels (one is "loud, nocturnal, strong" and another is "sticky, soft, wet") compared to semantically similar labels ("loud, nocturnal, strong" vs. "loud, heavy, strong") [71]. The earlier-discussed study with Mooney images [13] showed not only that verbal hints improved recognition, but also found that after being exposed to verbally labeled Mooney images, participants were better able to visually discriminate one Mooney image from another compared to a condition in which the same images were viewed equally often, but without being labeled. This effect was mediated by changes in P1 amplitudes and increases in alpha-band oscillations, especially in the left hemisphere. As we discuss in the section Making Sense of the Evidence, these results are consistent with labels preferentially activating category-diagnostic features - properties that most effectively distinguish category members from nonmembers which results in better recognition of category members and more efficient discrimination between members and non-members [36, 72]. 
Effects of language on detection. An even more basic perceptual process is simple detection wherein people are asked to indicate whether they have seen anything during a specific time period. Simple detection tasks require neither recognition nor discrimination (except for discriminating an objects from its background). When shown briefly-presented and backward masked letters, people's ability to correctly indicate whether a letter - any letter _was present, was affected by hearing the letter's name immediately prior [73]. It is as though the name prepared the visual system to detect (not just recognize) a class of shapes denoted by the label. A shortcoming of this study is that although brief masked presentation makes stimuli difficult to see, it does not block semantic processing [74], leaving open the possibility that hearing a label affected downstream processes rather than something as basic as visual detection. A later study [75] used continuous flash suppression (CFS) to suppress perceptual processing at a much earlier level [76]. In a typical CFS experiment, a meaningful image is presented to one eye while high contrast flashing patterns are presented to the other. The flashing patterns act to suppress awareness of the image through a form of binocular rivalry. Hearing a word (e.g., "pumpkin") prior to viewing a CFS display made an otherwise invisible image (e.g., of a pumpkin) visible. The detection advantage was limited to trials on which the verbal cue matched the suppressed stimulus: hearing "pumpkin" did not cause people to confabulate seeing pumpkins where none existed. Because images suppressed through CFS are not processed semantically, this detection benefit cannot be ascribed to downstream effects of language. Subsequent work supported the interpretation that the detection advantage stems from labels activating the shape of the to-be-detected object [77].

Another method of investigating the influence of language on visual awareness involves detecting stimuli in a stream of rapidly presented images. A classic finding is that when participants are asked to detect two targets $\left(\mathrm{T}_{1}\right.$ and $\mathrm{T}_{2}$ ) within a visual stream of non-target images, presenting $\mathrm{T}_{1}$ causes people to miss $\mathrm{T}_{2}$ if $\mathrm{T}_{2}$ occurs $200-500 \mathrm{~ms}$ after $\mathrm{T}_{1}$ - a so-called attentional blink [78]. A popular explanation is that ongoing processing of $\mathrm{T}_{1}$ hinders $\mathrm{T}_{2}$ 's access to a second processing stage that is necessary to produce a durable representation of the stimulus [79]. In a recent study [80], researchers used pictures of rare objects as the $\mathrm{T}_{2}$. When subjects previously associated the pictures with verbally-described functions (e.g., "this is an incubator for chicken eggs"), they showed an increase in conscious detection. This effect was predicted from modulations of the P1 component 
approximately $100 \mathrm{~ms}$ after stimulus presentation. In another study using the attentional blink paradigm it was shown that native Greek and Russian speakers, who distinguish categorically between light and dark shades of blue, showed boosted detection of $\mathrm{T}_{2}$ when it was marked by verbal contrast [48]. A P1 modulation for within- and between-category colors was registered in Greek participants (Russian speakers were not tested), and this modulation predicted their behavioral advantage on trials with lexically discriminated colors. In contrast, German speakers who do not habitually refer to light and dark shades of blue by different names showed no behavioral or electrophysiological differences between blue and green targets. In at least some cases, our native language predicts what we consciously perceive.

\section{Making sense of the evidence: Predictive processing and the reach of language into perception}

On a naive view of perception, the idea that language can affect what we see is absurd. How can language - a high-level cognitive process unique to humans - affect the seemingly low-level mechanisms subserving visual processing? In the words of the opening quote, language cannot "reach down into the retina and rewire the ganglion cells" [2]. But our conscious visual experiences and the processes involved in even the simplest of perceptual tasks cannot be reduced to the firing of retinal ganglion cells [45, 81]. On the view of perception as a process of predictive inference - investigated under the somewhat co-extensive banners of 'predictive processing', 'active inference' and 'hierarchical predictive coding' — perceptual experiences arise at the meeting-point of generative model-based predictions and sensory stimulation (evidence). Percepts reflect 'best-guesses' of the world and these guesses are informed by prior knowledge, current sensory evidence, and context-varying estimations of their relative reliability ('precision') [82-84]. This process is not unique to visual perception and may be a useful framework for processing in all modalities including the perception of pain (See Box 2).

There are two main ways in which language impinges on the predictive process - which roughly map onto the off-line and on-line distinction in Fig. 2. The first is what happens during language learning. Here, labels can be viewed as supervisory signals (just as they are in supervised neural networks that have shown impressive successes in image recognition). In effect, linguistic labels act like artificial tasks, prompting the learner to actively seek ways to discriminate the labeled positive examples from the negative ones. If this 
ball is labeled "red", what is it that made it "red" and not "green"? Exposure to linguistically labeled cases provides important information concerning the predictability of sensory patterns.

It is easy to see how labeled cases are critical for developing domain expertise. A trained botanist can learn to recognize thousands of plants and species by sight. In the absence of the teaching signals provided by language, there would need to be sufficient non-label-invoking tasks to drive all and only those wedges through a visually dense and confusing space. But the same process is also at work in the learning of other categories we may take for granted. In learning to name colors, we not only learn where in color space our particular language places lexical boundaries, but we learn that color is a domain worth separating from other aspects of visual experience such as texture - an abstraction we might not make were it not for (some) languages demanding that we learn a color vocabulary. An important further source of perception-relevant knowledge gleaned from language may come from exposure to its distributional structure. By simply minimizing prediction error of the labels (and their co-occurrences) as they occur in language input, it is possible to learn a surprising amount of semantic structure including relationships between perceptual features (Box 3).

Understanding this off-line role of language (Fig. 2a) is critical to understanding how language influences perception. The usefulness of "blue" or "pumpkin" in guiding perception hinges on first learning the association between these words and their referents. It is logically possible that as one learns a language, habitual use of its terms gradually yet permanently reshapes perceptual representations. Following this early "formative" period, however, language may no longer be actively involved in perception. However, findings that manipulating language during a perceptual task - for example through verbal interference and using trial-by-trial verbal cueing affects performance on a range of perceptual tasks is difficult to square with a purely off-line account. Rather, language appears to modulate perception in-the-moment.

This brings us to the second way language influences perception: by providing a categorical expectation within which incoming perceptual input is processed. Imagine that you need to recognize a cow as quickly and accurately as possible. This can be achieved by pre-activating the visual features that distinguish cows from non-cows. This suite of features is precisely what a categorical label like "cow" is well-designed to activate. And indeed, people are better able to recognize familiar images like that of a cow when it 
is preceded by its categorical label ("cow") than equally informative but less categorical nonverbal cues such as the sound of a cow mooing [72, 85]. (Though there is some evidence that nonverbal auditory cues may be more effective in simple detection tasks [86]). The idea that labels elicit categorical expectations can be cast in terms of 'category-based attention' [70, 87, 88]. For example, we can tell someone to attend to vehicles or to faces or to colors (instructions that rapidly warp neural representations across the visual hierarchy [89, 90]). As experimenters, we often take for granted our ability to use language to guide attention in this way, but consider the difficulty of placing a person into that attentional state without language. We can try to use alternatives: a picture of some vehicle, some face, a patch of color. But these are necessarily specific [91] and have limited power in cueing a categorical state [38, 72].

Viewed in this way, what makes linguistic cues different from nonlinguistic ones is their patterns of associations. Any perceptual experience of a car or cow or the color green is necessarily quite specific; with language in contrast, the same words are used to refer to a range of objects/events/relations; people learn that "car", "cow", and "green" can be used to refer to any member of these categories. This makes labels ideally suited for setting up the sorts of categorical (and relational) expectations that are difficult to set up effectively using nonlinguistic means. That said, the underlying mechanisms by which linguistic and non-linguistic cues set up expectations are likely to be much the same.

In short: learning a language allows us to use words and larger verbal constructions as a metabolically cheap and flexible means of modifying predictive cascades of ourselves and of others, altering what top-down information in brought in and how much influence it has at different levels of perceptual processing.

The predictive coding perspective may help to make sense of the limits on the effects of language on perception and the often-observed task sensitivity. For example, people who speak languages with different color naming schemes do not appear to differ in how small a color difference they are able to perceive (i.e., size of their just-noticeable difference) [54, 92]. Within a language too, the size of a just-noticeable-difference is not well correlated with the placement of lexicalized color categories [93]: and categorical color perception itself is surprisingly task-dependent [94, 95]. These findings have led some researchers to wonder whether such effects are limited to tasks that are somehow linguistic rather than "truly" perceptual [96]. For example, 
some have argued that "because labeling is not an inherent part of a visual process, ... we should not expect it to have a significant effect on visual appearance or discrimination ...the closer a color task is to language, the more likely it is that it will be affected by the terms in one's language" [97].

The predictive coding framework obviates the need to decide how linguistic or perceptual a given task is and instead poses the question of whether linguistic guidance helps to reduce prediction error [21]. In a task requiring discriminating small (largely within-category) differences in hue, linguistic guidance would be expected to do little. In a task requiring people to remember an item's exact position [98] or color [40, 99], the finding that people's memory is affected by categories (both linguistic and nonlinguistic) can be usefully modeled by merging continuous perceptual representations with more categorical (discrete) conceptual/linguistic ones [40] with the original perceptual representation left intact. Yet we continue to see influences of categories on tasks where memory demands are minimal (e.g., simultaneous discrimination or reproduction of a currently visible stimulus such as matching one color to another [40, 99]). One would think that in such tasks our decision mechanisms could simply draw on the earlier more continuous representation prior to it being "contaminated" by categorical codes. Yet as the data show, this is not always possible. On an alternative "perceptual warping" account, the merging of continuous and categorical information happens through top-down feedback of categorical representations onto (the more continuous) perceptual representations. The reason labels can affect visual discrimination and reproduction on this account is that the automatically activated labels are altering the lower-level perceptual representations themselves [38]. The level at which language has its effect is expected to depend on where in the perceptual hierarchy a change will reduce prediction error the most [cf. 100]. This is, of course, a rather vague claim and we recognize that much more rigorous work is required to precisely connect the idea of error minimization to patterns of behavior in experimental tasks. As a starting point, attempts to explain top-down effects on speech perception in terms of minimizing prediction error [101, 102] offer a promising direction. Despite difference conceptions of where precisely the merging of perceptual and categorical information is happening, what all these accounts have in common is that behavior in even low- level perceptual tasks is determined by more than bottom-up perceptual inputs. For language to change perception it hardly needs to "reach down into the retina" [45]. 


\section{Differences in behavior versus differences in subjective experience}

Does finding that people speaking different languages perform differently on some perceptual tasks mean that learning different languages causes us to literally see the world in a different way? Do results showing that language affects objective behavior on perceptual tasks mean that language affects how the world appears? Some think the answer is a clear no. One critic sums up such effects as "a passing flicker, that only painstaking experiment can reveal, in no way creating a different way of seeing the world" [103]. The experiments we review here indeed make painstaking attempts to rule out alternative explanations for the observed changes in behavior, attempting to demonstrate the perceptual nature of these effects. We have no doubt that many of these differences in accuracy and reaction times are not accompanied by substantive changes to subjective experience. This observation raises two questions.

What matters more: objective differences in behavior or subjective differences in experience? Imagine two participants (A and B) performing the same difficult discrimination task. Both inform us that they could not distinguish the items whatsoever. Participant A's data reveals chance-level performance. Participant B's reveals performance well above chance. Do we conclude that A's and B's perception was identical? Or do we put our trust in the observed difference in objective behavior? It is, of course, interesting to find dissociations between subjective experience and objective behavior, but faced with choosing a measure, there is good reason to choose one based on objective behavior.

Would we know a difference in subjective experience if it existed? The collective shock of the Internet and vision scientists on discovering \#theDress (https://en.wikipedia.org/wiki/The_dress) — and the continued shocks whenever new stimuli of this sort are discovered: the jacket, the shoe, Yanny or Laurel — shows just how strongly we assume that the same perceptual input should produce the same perceptual experience. It is only by comparing notes that we can appreciate that sometimes it does not. How often such discrepancies occur and whether they can be predicted by differences in our experiences (language among them) is yet to be determined. Importantly, effects of prior experiences on subjective appearance are not willy-nilly. There is no reason to expect \#theDress to appear differently to people speaking different languages. There is a theoretical reason to expect that it would appear differently to people who wake up early vs. those who 
sleep in, and, in fact, it does 104$]$.

Some have wondered why top-down effects on perception seem to be so difficult to experience subjectively compared to, for example, visual illusions [105]. The compellingness of the best visual illusions depends on our ability to flexibly manipulate the visual stimulus. For example, the Adelson grid causes us to see two identically shaded squares as having different lightness [106]. What makes such illusions so compelling is that we can experience changes to our subjective experience by covering up the inducer, at which point the two squares start to look identical. The problem is that we cannot manipulate conceptual knowledge or prior experience with language in this way. We cannot pause being English speakers or switch on-and-off our knowledge that a face being shown is our mother's. As experimenters, we can manipulate top-down influences somewhat, for example, by testing bilinguals in different languages [45], by down-regulating impacts of language through verbal interference or noninvasive neural stimulation, or by up-regulating them through overt presentation of labels [107]. When these manipulations do lead to differences in behavior, we can infer that our normal experience must be - to some extent - influenced by the linguistic factor being manipulated. Sometimes even these subtle manipulations lead to differences in subjective experience [108] (see also Box 4).

\section{Concluding Remarks}

We began by contrasting two perspectives on the relationship between language and perception. There is some irony that Sapir, whose view was not informed by any of the empirical findings we discuss, is much more on the mark than Pinker, who relegates the idea that language affects thinking and perceiving to a time when "scientists were in the dark about how thinking works or even how to study it" [2].

At one time, both language and perception were thought to be informationally encapsulated, their outputs feeding into domain-general cognitive systems, but not influencing one another [109]. The evidence we review here shows that language influences basic perceptual processing, affecting performance on tasks such as discrimination and detection, tasks that might seem to be wholly perceptual in nature. Far from a radical claim, this conclusion may naturally follow from viewing perception as an interactive system seeking to minimize prediction error. Becoming a language user requires that we become expert at categorizing thousands of visual percepts into named 
categories. This experience equips us not only with the ability to efficiently communicate about our perceptual experiences, but to then use these words to flexibly deploy task-relevant hypotheses within which incoming perceptual information can be made more meaningful (see Outstanding Questions).

\section{Box 1: Cross-linguistic differences in the language of perception}

Although all languages provide ways for describing perceptual experiences, and there are broad similarities in the naming systems, there are also surprisingly large differences in the details. Take just about any word that describes a perceptual property — "spicy", "triangle", "loud", "blue" — and you will find none to be universal [110, 111]. These lexical differences have often been minimized by pointing out that people can always invent words if they are needed [112]. But this confuses the potential for the actual. It is true that over decades or centuries languages change to meet new communicative demands. But this does not mean that an individual speaking a language lacking color words can, on their own, invent them! In the course of learning English, children become experts at naming (categorizing) some part of color space. In comparison, Lao speakers learn to categorize a far smaller part of color space (Fig. Ib). But, compared to English speakers, they have more consistent classification of certain odors [113]. People speaking either language can become expert categorizers in any domain, but having the requisite words as part of the core vocabulary ensures that all speakers do.

Another point of confusion concerns the relationship between the number of terms in a language and their use. It is not that languages with fewer color terms necessarily have terms that apply to larger regions of color space [see 114, for a model that connects naming consistency to communicative efficiency]. Rather, languages with fewer color terms sometimes have large

regions of color space without conventional names [113, 115] (Fig. I). Absent a conventional label, it is difficult (perhaps impossible) to cue the category. How do you get someone to attend to blues without being able to use "blue"?

\section{Box 2 The effect of language on the perception of pain}

Just as the proximate cause of visual experience are photons entering the retina, the proximate cause of peripheral pain is the stimulation of various thermal, chemical, and mechanical receptors. But just as visual perception 
(a)

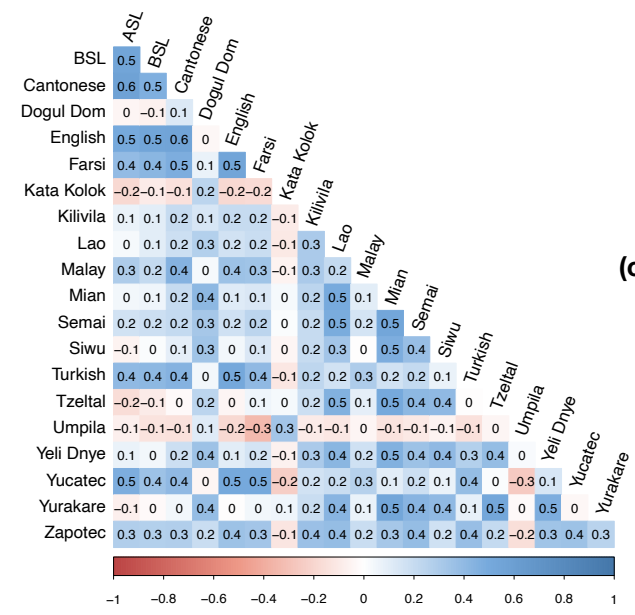

(b)

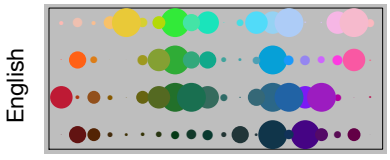

(c)
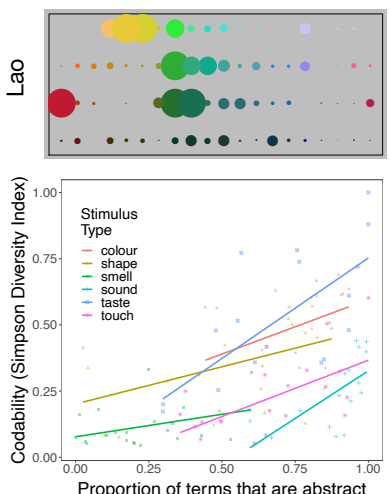

Figure I: Cross-linguistic differences in the language of perception. (a). Crosslinguistic correlations in color nameability for 40 Munsell color chips of maximum saturation; smaller numbers indicate that the most nameable colors in one language are not the same as those in another. ASL: American Sign Language; BSL: British Sign Language. (b). Nameability of maximally saturated colors in English and Lao (colors shown are RGB approximations of Munsell color chips). (c). For all perceptual modalities, greater nameability is associated with greater use of abstract terms (e.g., "yellow", "scratchy") as opposed to source-based terms ("lemon", "sandpaper"). Data shown are based on reanalysis of [113] and is made conservative by including phrasal heads only; "dark blue" and "light blue" are counted as the same response.

cannot be reduced to retinal stimulation, the experience of pain is not reducible to such stimulation. Of particular relevance to this review is the phenomenon of placebo analgesia in which the same stimulus is experienced as either more or less painful depending on a person's expectations [e.g., 116119]. The phenomenon of placebo analgesia is broadly consistent with the idea that perceived pain reflects both the properties of the external stimuli and the person's (certainty-weighed) expectations [120, 121]. Having expectations of more or less pain does not simply bias people to respond to an external stimulus more or less strongly. Rather, these expectations modulate nearly the entire physiological profile of pain [119, 122]. Some brain regions (e.g., posterior insula) continue to code the actual intensity of the stimulus somewhat independently of people's expectations, but this is ultimately irrelevant when we consider that our subjective experiences of pain 
tracks with physiological pain responses such as heart rate, skin conductance, and pupil size which are all modulated by our expectations [120]. Verbally induced expectations in particular — "I will now apply a cream that will help reduce the pain" - play an especially important role [116, 123-125].

It may be tempting to brush aside this example of language affecting perception as that of language simply being used as a tool to set up expectations. In principle, these expectations can be set up through other, nonlinguistic methods, for example, by learning to pair arbitrary shapes with a more or less painful stimulus [120]. But consider the difficulty of nonlinguistically conveying to a subject the idea that spreading this cream on their left arm will, in 15 minutes, reduce the amount of thermally-induced pain in their arm [123]. Even if, in principle, these expectations can be set up nonlinguistically (e.g., by associating the creme with a non-placebo analgesic) what language adds is fast, precise, and highly flexible deployment of these expectations [126].

\section{Box 3 Visual knowledge From Language Statistics}

Associating some discriminable stimuli with common names and others with different names - a process of acquired similarity and distinctiveness [127] - may be just one of the ways in which language "trains" perception. As we have long known, languages are not just form-meaning pairings, but are coherent symbolic systems [128]. Word meanings cannot be dissociated from word use. The meaning of "bedroom" derives in part from the existence of contrasting words ("bathroom", "kitchen") and the contexts in which these words are used [129]. What this means is that co-occurrence statistics between words can act as a kind of echo of real-world linkages and causal relationships. A learning system whose sole experience is language can learn a surprising amount about the world by running a self-supervised learning algorithm on the incoming language stream (e.g., by trying to predict the next word and minimizing the prediction error based on the word that is actually observed) [130, 131]).

As these learning algorithms are applied to larger amounts of text, we are realizing just how much structure people have "pushed" into the cooccurrence statistics of languages. Consider the observation that congenitally blind people - who have no perceptual experience with color whatsoever nevertheless know quite a bit about the color of various objects and the similarity structure of color space [132-135]. Recent investigations showed 
that it is possible to recover this type of information from distributional semantics alone [cf. 136, 137]. The finding that the distributional structure of languages contains rich information about visual appearance does not tell us how much people rely on it for learning about what things look like, but it does raise the possibility that distributional semantics may be an important teaching signal for our perceptual systems [138].

\section{Box 4: Language and Mental Imagery}

Conventional perceptual experiences are triggered by perceptual inputs from the outside world. Most of us are also able to entertain quasi-perceptual states in the form of mental imagery. Like conventional percepts, mental imagery can be triggered by external perceptual events. For example, seeing a friend's face may trigger a vivid mental image of the last time we saw her. Other times, what triggers visual imagery is language. When we want someone to experience the view from the hotel window without actually being there to see it, we do it with language. Most people also regularly use language directed at themselves, triggering mental images through inner speech [139]. As is now well known, imagery and perception engage overlapping neural circuits [140-142] and evoke similar representations of object categories [143].

Processing language that describes consistent visual motion in one direction has been shown to produce sufficiently vivid mental images to cause direction-selective motion adaptation in the visual system (i.e., cause a motion aftereffect illusion). One study [144] tested for motion aftereffects following explicit motion imagery and after processing language containing literal or metaphorical motion (without any instructions to imagine). The results demonstrate that processing language can spontaneously create sufficiently vivid mental images to produce direction-selective adaptation in the visual system.

It is interesting to consider what our visual imagery ability would be like in the absence of language altogether. Would our ability to form mental images be compromised if we had no language to help cue them? In a recent study [145, , preprint], researchers varied the amount of (verbally transmitted) knowledge participants learned about novel objects which they then either saw or had to imagine. The authors reasoned that greater semantic knowledge would lead to a stronger ability to reactivate the object's visual properties through top-down feedback. Semantic knowledge modu- 
lated early components of both object perception and visual imagery with similar P1 amplitude modulations in both tasks. Greater semantic knowledge also led to faster onset of visual imagery. These results show that in addition to influencing perceptual processing of actually-presented objects, verbally transmitted knowledge can shape mental imagery.

\section{Acknowledgments}

We thank Sean Roberts for help with Figure IB. Preparation of this manuscript was partially supported by NSF-PAC \#1734260 to GL.

\section{References}

[1] Sapir E. The Status of Linguistics as a Science. Language 1929;5:20714.

[2] Pinker S. The Language Instinct. New York: Harper Collins; 1994.

[3] Keane BP. Contour Interpolation: A Case Study in Modularity of Mind. Cognition 2018;174:1-18. URL: https://www.ncbi.nlm.nih. gov/pmc/articles/PMC6667224/. doi:10.1016/j.cognition.2018. 01.008 .

[4] Biederman I. Recognition-by-components: A theory of human image understanding. Psychological Review 1987;94(2):115-47. doi:10.1037/ 0033-295X.94.2.115.

[5] Treue S, Husain M, Andersen RA. Human perception of structure from motion. Vision Research 1991;31(1):59-75. URL: http://www. sciencedirect.com/science/article/pii/004269899190074F. doi:10.1016/0042-6989(91) 90074-F.

[6] Erlikhman G, Strother L, Barzakov I, Caplovitz GP. On the Legibility of Mirror-Reflected and Rotated Text. Symmetry 2017;9(3):28. URL: https ://www .mdpi . com/2073-8994/9/3/28. doi:10.3390/sym9030028. 
[7] Young AW, Burton AM. Are We Face Experts? Trends in Cognitive Sciences 2018;22(2):100-10. URL: http://www. sciencedirect.com/science/article/pii/S1364661317302474. doi:10.1016/j.tics.2017.11.007.

[8] Vrins S, de Wit TCJ, van Lier R. Bricks, butter, and slices of cucumber: Investigating semantic influences in amodal completion. Perception 2009;38(1):17-29.

[9] Risko EF, Dixon M, Besner D, Ferber S. The ties that keep us bound: Top-down influences on the persistence of shape-from-motion. Consciousness and Cognition 2006;15(2):47583. URL: http://www.sciencedirect.com/science/article/pii/ S1053810005001509. doi:16/j.concog. 2005.11.004.

[10] Moore C, Cavanagh P. Recovery of 3D volume from 2tone images of novel objects. Cognition 1998;67(1-2):4571. URL: http://www.sciencedirect.com/science/article/pii/ S0010027798000146. doi:10.1016/S0010-0277(98)00014-6.

[11] Bulthoff I, Bulthoff H, Sinha P. Top-down influences on stereoscopic depth-perception. Nature Neuroscience 1998;1(3):254-7. URL: ISI: 000076361200018.

[12] Teufel C, Dakin SC, Fletcher PC. Prior object-knowledge sharpens properties of early visual feature-detectors. Scientific Reports 2018;8(1):1-12. URL: https://www.nature.com/articles/ s41598-018-28845-5. doi:10.1038/s41598-018-28845-5.

[13] Samaha J, Boutonnet B, Postle BR, Lupyan G. Effects of meaningfulness on perception: Alpha-band oscillations carry perceptual expectations and influence early visual responses. Scientific Reports 2018;8(1):6606. URL: http://www.nature.com/articles/ s41598-018-25093-5. doi:10.1038/s41598-018-25093-5.

[14] Yuille A, Kersten D. Vision as Bayesian inference: Analysis by synthesis? Trends in Cognitive Sciences 2006;10(7):3018. URL: http://www.sciencedirect.com/science/article/pii/ S1364661306001264. doi:10.1016/j.tics.2006.05.002. 
[15] Dehaene-Lambertz G, Dupoux E, Gout A. Electrophysiological correlates of phonological processing: A cross-linguistic study. Journal of Cognitive Neuroscience 2000;12(4):635-47. doi:10.1162/ 089892900562390 .

[16] Kazanina N, Phillips C, Idsardi W. The influence of meaning on the perception of speech sounds. Proceedings of the National Academy of Sciences 2006;103(30):11381-6. URL: https://www.pnas.org/ content/103/30/11381. doi:10.1073/pnas.0604821103.

[17] Samuel AG. Lexical Activation Produces Potent Phonemic Percepts. Cognitive Psychology 1997;32(2):97-127. URL: http://www. sciencedirect.com/science/article/pii/S0010028597906460. doi:10.1006/cogp.1997.0646.

[18] McClelland J, Mirman D, Holt L. Are there interactive processes in speech perception? Trends in Cognitive Sciences 2006;10(8):363-9.

[19] Cohen L, Lehéricy S, Chochon F, Lemer C, Rivaud S, Dehaene S. Language-specific tuning of visual cortex? Functional properties of the Visual Word Form Area. Brain 2002;125(5):105469. URL: http://brain. oxfordjournals.org/content/125/5/ 1054. abstract. doi:10.1093/brain/awf094.

[20] Clark A. Whatever Next? Predictive Brains, Situated Agents, and the Future of Cognitive Science. Behavioral and Brain Sciences 2013;36(3):181-204.

[21] Lupyan G. Cognitive Penetrability of Perception in the Age of Prediction: Predictive Systems are Penetrable Systems. Review of Philosophy and Psychology 2015;6(4):547-69. URL: http: //link. springer. com/article/10.1007/s13164-015-0253-4. doi:10.1007/s13164-015-0253-4.

[22] O'Callaghan C, Kveraga K, Shine JM, Adams Jr. RB, Bar M. Predictions penetrate perception: Converging insights from brain, behaviour and disorder. Consciousness and Cognition 2016;URL: http://www. sciencedirect.com/science/article/ pii/S1053810016300824. doi:10.1016/j. concog. 2016.05.003. 
[23] Harnad S. Cognition is categorization. In: Cohen H, Lefebvre C, editors. Handbook of Categorization in Cognitive Science. San Diego, CA: Elsevier Science; 2005, p. 20-45.

[24] Hsieh PJ, Vul E, Kanwisher N. Recognition alters the spatial pattern of FMRI activation in early retinotopic cortex. Journal of Neurophysiology 2010;103(3):1501-7. doi:10.1152/jn.00812.2009.

[25] Vandenbroucke ARE, Fahrenfort JJ, Meuwese JDI, Scholte HS, Lamme VaF. Prior Knowledge about Objects Determines Neural Color Representation in Human Visual Cortex. Cerebral Cortex (New York, NY: 1991) 2016;26(4):1401-8. doi:10.1093/cercor/bhu224.

[26] Pylyshyn Z. Is vision continuous with cognition? The case for cognitive impenetrability of visual perception. Behavioral and Brain Sciences 1999;22(3):341-65.

[27] Dils AT, Boroditsky L. Processing unrelated language can change what you see. Psychonomic Bulletin \& Review 2010;17(6):882-8. doi:10. 3758/PBR.17.6.882.

[28] Firestone C, Scholl B. Cognition does not affect perception: Evaluating the evidence for 'top-down' effects. The Behavioral and Brain Sciences 2016;39:1-77. doi:10.1017/S0140525X15000965.

[29] Luck SJ. Overview of common ERP components. In: An Introduction to the Event-Related Potential Technique; second ed. Cambridge, Massachusetts: MIT Press. ISBN 978-0-262-52585-5; 2014, p. 71-118.

[30] Rossion B, Jacques C. The N170: Understanding the Time Course of Face Perception in the Human Brain. In: The Oxford Handbook of Event-Related Potential Components. Oxford University Press. ISBN 978-0-19-994035-6; 2011, p. 115-42. doi:10.1093/oxfordhb/ 9780195374148.001 .0001 .

[31] Tanaka J, Curran T. A neural basis for expert object recognition. Psychological Science 2001;12(1):43-7.

[32] Kutas M, Federmeier KD. Thirty years and counting: Finding meaning in the N400 component of the event-related brain potential (ERP). 
Annual Review of Psychology 2011;62:621-47. doi:10.1146/annurev . psych.093008.131123.

[33] Rabovsky M, Hansen SS, McClelland JL. Modelling the N400 brain potential as change in a probabilistic representation of meaning. Nature Human Behaviour 2018;2(9):693-705. doi:10.1038/ s41562-018-0406-4.

[34] Abdel Rahman R, Sommer W. Seeing what we know and understand: How knowledge shapes perception. Psychonomic Bulletin \& Review 2008;15(6):1055-63. URL: http://pbr.psychonomic-journals.org/ content/15/6/1055. abstract. doi:10.3758/PBR.15.6.1055.

[35] Rabovsky M, Sommer W, Abdel Rahman R. Depth of conceptual knowledge modulates visual processes during word reading. Journal of Cognitive Neuroscience 2012;24(4):990-1005. doi:10.1162/jocn_a_ 00117 .

[36] Boutonnet B, Lupyan G. Words jump-start vision: A label advantage in object recognition. The Journal of Neuroscience 2015;32(25):932935. doi:10.1523/JNEUROSCI .5111-14.2015.

[37] Feldman NH, Griffiths TL, Morgan JL. The influence of categories on perception: Explaining the perceptual magnet effect as optimal statistical inference. Psychological Review 2009;116(4):752-82. doi:10. $1037 / \mathrm{a} 0017196$.

[38] Forder L, Lupyan G. Hearing words changes color perception: Facilitation of color discrimination by verbal and visual cues. Journal of Experimental Psychology: General 2019;148(7):1105-23. doi:10.1037/ xge0000560.

[39] Athanasopoulos P, Wiggett A, Dering B, Kuipers JR, Thierry G. The Whorfian mind: Electrophysiological evidence that language shapes perception. Communicative \& Integrative Biology 2009;2(4):332-4. doi:10.4161/cib.2.4.8400.

[40] Cibelli E, Xu Y, Austerweil JL, Griffiths TL, Regier T. The Sapir-Whorf Hypothesis and Probabilistic Inference: Evidence from the Domain of Color. PLOS ONE 2016;11(7):e0158725. 
URL: http://journals.plos.org/plosone/article?id=10.1371/ journal.pone.0158725. doi:10.1371/journal pone.0158725.

[41] Regier T, Kay P. Language, thought, and color: Whorf was half right. Trends in Cognitive Sciences 2009;13(10):43946. URL: http://www.sciencedirect.com/science/article/ B6VH9-4X3H2JD-2/2/6e39b7cac5f9c3d5c0ca53182c0d330b. doi:10. $1016 /$ j.tics.2009.07.001.

[42] Roberson D. Color Categories Are Culturally Diverse in Cognition as Well as in Language. Cross-Cultural Research 2005;39(1):56-71. URL: http://journals.sagepub.com/doi/abs/ 10.1177/1069397104267890. doi:10.1177/1069397104267890.

[43] Anderson W, Biggam CP, Hough C, Kay C, editors. Colour Studies: A Broad Spectrum. Amsterdam: John Benjamins Publishing Company; 2014. ISBN 978-90-272-1219-1 978-90-272-6919-5. URL: http://www . jbe-platform. com/content/books/9789027269195. doi:10.1075/z. 191.

[44] Ocelák R. "Categorical Perception" and Linguistic Categorization of Color. Review of Philosophy and Psychology 2016;7(1):55-70. URL: https://link-springer-com.ezproxy. library.wisc.edu/article/10.1007/s13164-015-0237-4. doi:10. 1007/s13164-015-0237-4.

[45] Athanasopoulos P, Casaponsa A. The Whorfian brain: Neuroscientific approaches to linguistic relativity. Cognitive Neuropsychology 2020;0(0):1-20. URL: https://doi.org/10.1080/02643294.2020. 1769050. doi:10.1080/02643294.2020.1769050.

[46] Winawer J, Witthoft N, Frank M, Wu L, Wade A, Boroditsky L. Russian blues reveal effects of language on color discrimination. Proceedings of the National Academy of Sciences of the United States of America $2007 ; 104(19): 7780-5$.

[47] Roberson D, Pak H, Hanley JR. Categorical perception of colour in the left and right visual field is verbally mediated: Evidence from Korean. Cognition 2008;107(2):75262. URL: http://www.sciencedirect.com/science/article/ 
B6T24-4PVY2XR-1/2/3b1d0525225794ef4c5d19956a236564. doi:10. 1016/j.cognition.2007.09.001.

[48] Maier M, Abdel Rahman R. Native Language Promotes Access to Visual Consciousness. Psychological Science 2018;29(11):1757-72. doi:10.1177/0956797618782181.

[49] Thierry G, Athanasopoulos P, Wiggett A, Dering B, Kuipers JR. Unconscious effects of language-specific terminology on preattentive color perception. Proceedings of the National Academy of Sciences 2009;106(11):4567-70. doi:10.1073/pnas.0811155106.

[50] Forder L, He X, Franklin A. Colour categories are reflected in sensory stages of colour perception when stimulus issues are resolved. PLOS ONE 2017;12(5):e0178097. URL: http://journals.plos. org/plosone/article?id=10.1371/journal . pone. 0178097. doi:10. 1371/journal. pone. 0178097.

[51] Boutonnet B, Dering B, Viñas-Guasch N, Thierry G. Seeing Objects through the Language Glass. Journal of Cognitive Neuroscience 2013;25(10):1702-10. URL: https ://doi .org/10.1162/jocn_ a_00415. doi:10.1162/jocn_a_00415.

[52] Ozgen E, Davies I. Acquisition of categorical color perception: A perceptual learning approach to the linguistic relativity hypothesis. Journal of Experimental Psychology-General 2002;131(4):477-93.

[53] Zhou K, Mo L, Kay P, Kwok VPY, Ip TNM, Tan LH. Newly trained lexical categories produce lateralized categorical perception of color. Proceedings of the National Academy of Sciences 2010;107(22):99748. URL: http://www. pnas.org/content/107/22/9974.abstract. doi:10.1073/pnas.1005669107.

[54] Grandison A, Sowden PT, Drivonikou VG, Notman LA, Alexander I, Davies IRL. Chromatic Perceptual Learning but No Category Effects without Linguistic Input. Frontiers in Psychology 2016;7. URL: https://www.ncbi.nlm.nih.gov/pmc/articles/ PMC4879779/. doi:10.3389/fpsyg.2016.00731.

[55] Gilbert A, Regier T, Kay P, Ivry R. Whorf hypothesis is supported in the right visual field but not the left. Proceedings of the National 
Academy of Sciences of the United States of America 2006;103(2):48994.

[56] Pilling M, Wiggett A, Ozgen E, Davies I. Is color "categorical perception" really perceptual? Memory \& Cognition 2003;31(4):538-51. URL: ISI : 000183961900005.

[57] Roberson D, Damjanovic L, Pilling M. Categorical perception of facial expressions: Evidence for a "category adjustment" model. Memory \& cognition 2007;35(7):1814-29.

[58] Drivonikou G, Kay P, Regier T, Ivry R, Gilbert A, Franklin A, et al. Further evidence that Whorfian effects are stronger in the right visual field than the left. Proceedings of the National Academy of Sciences of the United States of America 2007;104(3):1097-102.

[59] Zhong W, Li Y, Huang Y, Li H, Mo L. Is the Lateralized Categorical Perception of Color a Situational Effect of Language on Color Perception? Cognitive Science 2018;42(1):350-64. doi:10.1111/cogs.12493.

[60] Mo L, Xu G, Kay P, Tan LH. Electrophysiological evidence for the left-lateralized effect of language on preattentive categorical perception of color. Proceedings of the National Academy of Sciences 2011;108(34):14026-30. URL: http://www.pnas.org/content/108/ 34/14026 . abstract. doi:10.1073/pnas.1111860108.

[61] Ting Siok W, Kay P, Wang WSY, Chan AHD, Chen L, Luke KK, et al. Language regions of brain are operative in color perception. Proceedings of the National Academy of Sciences 2009;106(20):81405. URL: http://www. pnas.org/content/106/20/8140.abstract. doi:10.1073/pnas.0903627106.

[62] Tan LH, Chan AHD, Kay P, Khong PL, Yip LKC, Luke KK. Language affects patterns of brain activation associated with perceptual decision. Proceedings of the National Academy of Sciences 2008;105(10):40049. URL: http://www. pnas .org/content/105/10/4004. doi:10.1073/ pnas. 0800055105 .

[63] Kosslyn SM, Koenig O, Barrett A, Cave CB, Tang J, Gabrieli JD. Evidence for two types of spatial representations: Hemispheric special- 
ization for categorical and coordinate relations. Journal of Experimental Psychology Human Perception and Performance 1989;15(4):723-35. URL: http://www.ncbi.nlm.nih.gov/pubmed/2531207.

[64] Holmes KJ, Wolff P. Does categorical perception in the left hemisphere depend on language? Journal of Experimental Psychology General 2012;141(3):439-43. doi:10.1037/a0027289.

[65] Witzel C, Gegenfurtner KR. Is there a lateralized category effect for color? Journal of Vision 2011;11(12). URL: http: //www. journalofvision.org/content/11/12/16. abstract. doi:10. 1167/11.12.16.

[66] Brederoo SG, Nieuwenstein MR, Cornelissen FW, Lorist MM. Reproducibility of visual-field asymmetries: Nine replication studies investigating lateralization of visual information processing. Cortex; a Journal Devoted to the Study of the Nervous System and Behavior 2019;111:100-26. doi:10.1016/j.cortex.2018.10.021.

[67] Wright O, Davies IRL, Franklin A. Whorfian effects on colour memory are not reliable. The Quarterly Journal of Experimental Psychology 2015;68(4):745-58. URL: https://doi .org/10.1080/17470218. 2014.966123. doi:10.1080/17470218.2014.966123.

[68] Souza AS, Skóra Z. The interplay of language and visual perception in working memory. Cognition 2017;166:277-97. doi:10.1016/ j. cognition.2017.05.038.

[69] Lupyan G, Spivey M. Perceptual processing is facilitated by ascribing meaning to novel stimuli. Current Biology 2008;18(10):R410-2.

[70] Lupyan G. The conceptual grouping effect: Categories matter (and named categories matter more). Cognition 2008;108(2):566-77.

[71] Gauthier I, James T, Curby K, Tarr M. The influence of conceptual knowledge on visual discrimination. Cognitive Neuropsychology 2003;20(3-6):507-23. URL: ISI:000184129000013.

[72] Edmiston P, Lupyan G. What makes words special? Words as unmotivated cues. Cognition 2015;143:93-100. doi:doi:10.1016/j. cognition.2015.06.008. 
[73] Lupyan G, Spivey M. Making the invisible visible: Auditory cues facilitate visual object detection. PLoS ONE 2010;5(7):e11452. doi:10 . 1371/journal. pone. 0011452 .

[74] Kouider S, Dehaene S. Levels of processing during non-conscious perception: A critical review of visual masking. Philosophical Transactions of the Royal Society B: Biological Sciences 2007;362(1481):857-75. URL: https://www.ncbi.nlm.nih.gov/pmc/ articles/PMC2430002/. doi:10.1098/rstb.2007.2093.

[75] Lupyan G, Ward EJ. Language can boost otherwise unseen objects into visual awareness. Proceedings of the National Academy of Sciences 2013;110(35):14196-201. URL: http://www.pnas.org/content/ early/2013/08/08/1303312110. doi:10.1073/pnas.1303312110.

[76] Pasley BN, Mayes LC, Schultz RT. Subcortical discrimination of unperceived objects during binocular rivalry. Neuron 2004;42(1):163-72. doi:10.1016/s0896-6273(04)00155-2.

[77] Noorman S, Neville DA, Simanova I. Words affect visual perception by activating object shape representations. Scientific Reports 2018;8(1):14156. URL: https://www.nature.com/articles/ s41598-018-32483-2. doi:10.1038/s41598-018-32483-2.

[78] Raymond JE, Shapiro KL, Arnell KM. Temporary suppression of visual processing in an RSVP task: An attentional blink? Journal of Experimental Psychology: Human Perception and Performance 1992;18(3):849-60. doi:10.1037//0096-1523.18.3.849.

[79] Chun MM, Potter MC. A two-stage model for multiple target detection in rapid serial visual presentation. Journal of Experimental Psychology: Human Perception and Performance 1995;21(1):109-27. doi:10.1037/ /0096-1523.21.1.109.

[80] Weller PD, Rabovsky M, Abdel Rahman R. Semantic Knowledge Enhances Conscious Awareness of Visual Objects. Journal of Cognitive Neuroscience 2019;31(8):1216-26. doi:10.1162/jocn_a_01404.

[81] Foxe J, Simpson G. Flow of activation from V1 to frontal cortex in humans - A framework for defining "early" visual processing. Experimental Brain Research 2002;142(1):139-50. URL: ISI : 000173172800013. 
[82] De Lange F, Heilbron M, Kok P. How do expectations shape perception? Trends in Cognitive Science 2018;XXII(9):764-79.

[83] Clark A. Surfing Uncertainty: Prediction, Action, and the Embodied Mind. New York: Oxford University Press; 2016.

[84] Hohwy J. The Predictive Mind. New York, N.Y.: Oxford University Press; 2013. ISBN 978-0-19-968673-5.

[85] Lupyan G, Thompson-Schill S. The evocative power of words: Activation of concepts by verbal and nonverbal means. Journal of Experimental Psychology-General 2012;141(1):170-86. doi:10.1037/a0024904.

[86] Chen YC, Spence C. Crossmodal semantic priming by naturalistic sounds and spoken words enhances visual sensitivity. Journal of Experimental Psychology Human Perception and Performance 2011;37(5):1554-68. doi:10.1037/a0024329.

[87] Yu CP, Maxfield JT, Zelinsky GJ. Searching for Category-Consistent Features: A Computational Approach to Understanding Visual Category Representation. Psychological Science 2016;27(6):87084. URL: http://dx.doi.org/10.1177/0956797616640237. doi:10. $1177 / 0956797616640237$.

[88] Nako R, Wu R, Eimer M. Rapid guidance of visual search by object categories. Journal of Experimental Psychology Human Perception and Performance 2014;40(1):50-60. doi:10.1037/a0033228.

[89] Çukur T, Nishimoto S, Huth AG, Gallant JL. Attention during natural vision warps semantic representation across the human brain. Nature Neuroscience 2013;16(6):763-70. URL: http://www. nature. com/neuro/journal/v16/n6/nn.3381/metrics/news. doi:10.1038/ nn.3381.

[90] Brouwer GJ, Heeger DJ. Categorical Clustering of the Neural Representation of Color. The Journal of Neuroscience 2013;33(39):15454-65. URL: http://www.ncbi.nlm.nih.gov/pmc/articles/PMC3782623/. doi:10.1523/JNEUROSCI . 2472-13.2013. 
[91] Hout MC, Goldinger SD. Target templates: The precision of mental representations affects attentional guidance and decision-making in visual search. Attention, Perception \& Psychophysics 2015;77(1):128-49. doi:10.3758/s13414-014-0764-6.

[92] Roberson D, Hanley JR, Pak H. Thresholds for color discrimination in English and Korean speakers. Cognition 2009;112(3):482-7. doi:10 . 1016/j.cognition.2009.06.008.

[93] Witzel C, Gegenfurtner KR. Categorical sensitivity to color differences. Journal of Vision 2013;13(7):1. URL: http://www . journalof vision. org/content/13/7/1. doi:10.1167/13.7.1.

[94] Webster MA, Kay P. Color categories and color appearance. Cognition 2012;122(3):375-92. URL: http://www . sciencedirect.com/science/article/pii/S0010027711002794. doi:10.1016/j.cognition.2011.11.008.

[95] Witzel C, Gegenfurtner KR. Categorical facilitation with equally discriminable colors. Journal of Vision 2015;15(8):22-. URL: http:// jov . arvojournals .org/article. aspx?articleid=2381517. doi:10. $1167 / 15.8 .22$.

[96] Gleitman L, Papafragou A. New Perspectives on Language and Thought. In: Holyoak K, Morrison R, editors. The Oxford Handbook of Thinking and Reasoning. Oxford University Press. ISBN 9780199734689; 2012, p. 543-68. URL: https://www.oxfordhandbooks.com/view/10.1093/oxfordhb/ 9780199734689.001.0001/oxfordhb-9780199734689-e-28. doi:10.1093/oxfordhb/9780199734689.013.0028.

[97] Winawer J, Witthoft N. Effects of Color Terms on Color Perception and Cognition. In: Shamey R, editor. Encyclopedia of Color Science and Technology. Berlin, Heidelberg: Springer. ISBN 978-3-642-27851-8; 2020, p. 1-9. URL: https://doi.org/10.1007/978-3-642-27851-8_ 77-5. doi:10.1007/978-3-642-27851-8_77-5.

[98] Huttenlocher J, Hedges L, Duncan S. Categories and Particulars - Prototype Effects in Estimating Spatial Location. Psychological Review 1991;98(3):352-76. URL: ISI : A1991FX73300003. 
[99] Bae GY, Olkkonen M, Allred SR, Flombaum JI. Why some colors appear more memorable than others: A model combining categories and particulars in color working memory. Journal of Experimental Psychology: General 2015;144(4):744-63. doi:10.1037/xge0000076.

[100] Ahissar M, Hochstein S. The reverse hierarchy theory of visual perceptual learning. Trends in Cognitive Sciences 2004;8(10):457-64.

[101] Sohoglu E, Davis MH. Perceptual learning of degraded speech by minimizing prediction error. Proceedings of the National Academy of Sciences 2016;113(12):E1747-56. URL: https://www.pnas.org/ content/113/12/E1747. doi:10.1073/pnas.1523266113.

[102] Cope TE, Sohoglu E, Sedley W, Patterson K, Jones PS, Wiggins $\mathrm{J}$, et al. Evidence for causal top-down frontal contributions to predictive processes in speech perception. Nature Communications 2017:8(1):2154. URL: https://www .nature.com/articles/ s41467-017-01958-7. doi:10.1038/s41467-017-01958-7.

[103] McWhorter JH. The Language Hoax: Why the World Looks the Same in Any Language. Oxford ; New York: Oxford University Press; 2014. ISBN 978-0-19-936158-8.

[104] Wallisch P. Illumination assumptions account for individual differences in the perceptual interpretation of a profoundly ambiguous stimulus in the color domain: "The dress". Journal of Vision 2017;17(4):5. URL: https://jov.arvojournals.org/article.aspx?articleid= 2617976. doi:10.1167/17.4.5.

[105] Firestone C, Scholl BJ. Can you experience 'top-down' effects on perception?: The case of race categories and perceived lightness. Psychonomic Bulletin \& Review 2015;22(3):694-700. URL: http: //link. springer.com/article/10.3758/s13423-014-0711-5. doi:10.3758/s13423-014-0711-5.

[106] Adelson E. Perceptual Organization and the Judgment of Brightness. $\quad$ Science 1993;262(5142):2042-4. URL: http: //apps. isiknowledge. com. proxy. library. cornell. edu/full record.do? product=WOS\&search $\_$mode=GeneralSearch\&qid=1\&SID= 4FGd@CFi7G@c83f JhP5\&page $=1 \&$ doc $=1$. 
[107] Perry LK, Lupyan G. What the online manipulation of linguistic activity can tell us about language and thought. Frontiers in Behavioral Neuroscience 2013;7::122. URL: http://www.frontiersin. org/Behavioral_Neuroscience/10.3389/fnbeh.2013.00122/full. doi:10.3389/fnbeh. 2013.00122.

[108] Lupyan G. Changing what you see by changing what you know: The role of attention. Frontiers in Psychology 2017;8(1055). URL: http://journal.frontiersin.org/article/10.3389/fpsyg. $2017.00553 /$ abstract. doi:10.3389/fpsyg. 2017.00553.

[109] Fodor J. The Modularity of Mind. Cambridge, MA: MIT Press; 1983.

[110] Wierzbicka A. Semantics: Primes and Universals. Oxford University Press, UK; 1996. URL: http://books.google.com/books?hl=en\& Ir=\&id=ZN029Pmbnu4C\&o $i=f$ nd\&pg=PA3\&dq=info: QazMfnERxREJ : scholar . google. com\&ots=u-f4yd6ow J\&s ig=JYdRS-9zbrFun-1S4B_ hOGOHFdY.

[111] Evans N, Levinson S. The myth of language universals: Language diversity and its importance for cognitive science. Behavioral and Brain Sciences 2009;32(05):429. URL: http://apps.isiknowledge.com.ezproxy.library.wisc.edu/ full_record.do?product=UA\&search_mode=GeneralSearch\& qid=3\&SID=2Em9JnHdfCf 7LAKME4 $j$ \&page=1\&doc=2\&colname=WOS. doi:10.1017/S0140525X0999094X.

[112] Pullum GK. The Great Eskimo Vocabulary Hoax. Natural Language \& Linguistic Theory 1989;7(2):275-81. URL: http://dx.doi .org/10. 1007/BF00138079. doi:10.1007/BF00138079.

[113] Majid A, Roberts SG, Cilissen L, Emmorey K, Nicodemus B, O'Grady $\mathrm{L}$, et al. Differential coding of perception in the world's languages. Proceedings of the National Academy of Sciences 2018;115(45):11369-76. URL: http://www.pnas.org/content/115/45/11369. doi:10.1073/ pnas. 1720419115 .

[114] Zaslavsky N, Kemp C, Regier T, Tishby N. Efficient compression in color naming and its evolution. Proceedings of the National Academy 
of Sciences 2018;115(31):7937-42. URL: https://www.pnas.org/ content/115/31/7937. doi:10.1073/pnas .1800521115.

[115] Gibson E, Futrell R, Jara-Ettinger J, Mahowald K, Bergen L, Ratnasingam S, et al. Color naming across languages reflects color use. Proceedings of the National Academy of Sciences 2017;114(40):10785-90. URL: http://www.pnas.org/content/114/40/10785. doi:10.1073/ pnas. 1619666114 .

[116] Brown C, Seymour B, Boyle Y, El-Deredy W, Jones A. Modulation of pain ratings by expectation and uncertainty: Behavioral characteristics and anticipatory neural correlates. Pain 2008;135:240-50.

[117] Pollo A, Vighetti S, Rainero I, Benedetti F. Placebo analgesia and the heart. Pain 2003;102(1-2):125-33.

[118] Medoff ZM, Colloca L. Placebo analgesia: Understanding the mechanisms. Pain management 2015;5(2):89-96. URL: https://www.ncbi. nlm.nih.gov/pmc/articles/PMC4388042/. doi:10.2217/pmt.15.3.

[119] Colloca L, Klinger R, Flor H, Bingel U. Placebo analgesia: Psychological and neurobiological mechanisms. Pain 2013;154(4):511-4. URL: https://www.ncbi.nlm.nih.gov/pmc/ articles/PMC3626115/. doi:10.1016/j.pain.2013.02.002.

[120] Geuter S, Boll S, Eippert F, Büchel C. Functional dissociation of stimulus intensity encoding and predictive coding of pain in the insula. eLife 2017;6:e24770. URL: https://doi .org/10.7554/eLife.24770. doi:10.7554/eLife. 24770 .

[121] Büchel C, Geuter S, Sprenger C, Eippert F, al. e. Placebo analgesia: A predictive coding perspective. Neuron 2014;81(6):1223-39.

[122] Wager TD, Rilling JK, Smith EE, Sokolik A, Casey KL, Davidson RJ, et al. Placebo-Induced Changes in fMRI in the Anticipation and Experience of Pain. Science 2004;303(5661):1162-7. URL: https: //science.sciencemag.org/content/303/5661/1162. doi:10.1126/ science. 1093065 . 
[123] Watson A, El-Deredy W, Bentley DE, Vogt BA, Jones AKP. Categories of placebo response in the absence of site-specific expectation of analgesia. Pain 2006;126(1):115-22. URL: http://www. sciencedirect.com/science/article/pii/S0304395906003447. doi:10.1016/j.pain.2006.06.021.

[124] Benedetti F, Pollo A, Lopiano L, Lanotte M, Vighetti S, Rainero I. Conscious Expectation and Unconscious Conditioning in Analgesic, Motor, and Hormonal Placebo/Nocebo Responses. Journal of Neuroscience 2003;23(10):4315-23. URL: https://www. jneurosci.org/ content/23/10/4315. doi:10.1523/JNEUROSCI . 23-10-04315. 2003.

[125] Colloca L, Miller FG. How placebo responses are formed: A learning perspective. Philosophical Transactions of the Royal Society B: Biological Sciences 2011;366(1572):1859-69. URL: https://www.ncbi. nlm.nih.gov/pmc/articles/PMC3130403/. doi:10.1098/rstb.2010. 0398.

[126] Lupyan G, Clark A. Words and the World: Predictive coding and the language-perception-cognition interface. Current Directions in Psychological Science 2015;24(4):279-84. doi:10.1177/0963721415570732.

[127] Rossman I, Goss A. The acquired distinctiveness of cues: The role of discriminative verbal responses in facilitating the acquisition of discriminative motor responses. Journal of Experimental Psychology 1951;42(3):173-82. URL: http://www.ncbi.nlm.nih.gov/pubmed/ 14880669 .

[128] de Saussure F. Course in General Linguistics. Columbia University Press; 1916. ISBN 978-0-231-52795-8.

[129] Boleda G. Distributional Semantics and Linguistic Theory. Annual Review of Linguistics 2020;Accepted. URL: http://arxiv.org/abs/ 1905.01896. doi:10.1146/annurev-linguistics-011619-030303. arXiv: 1905.01896 .

[130] Elman J. An alternative view of the mental lexicon. Trends in Cognitive Sciences 2004;8(7):301-6. doi:10.1016/j.tics.2004.05.003. 
[131] Baroni M, Dinu G, Kruszewski G. Don't count, predict! A systematic comparison of context-counting vs. context-predicting semantic vectors. In: Proceedings of the 52nd Annual Meeting of the Association for Computational Linguistics. Baltimore, MD; 2014, p. 238-47. URL: http://anthology.aclweb.org/P/P14/P14-1023.pdf.

[132] Dimitrova-Radojichikj D. Concepts of Colors in Children with Congenital Blindness. Journal of Special Education and Rehabilitation 2015;16(1-2):7-16. URL: http://doi.org/10.1515/ JSER-2015-0001.

[133] Shepard RN, Cooper LA. Representation of Colors in the Blind, ColorBlind, and Normally Sighted. Psychological Science 1992;3(2):97104. URL: https://doi.org/10.1111/j.1467-9280.1992.tb00006. x. doi:10.1111/j.1467-9280.1992.tb00006.x.

[134] Lenci A, Baroni M, Cazzolli G, Marotta G. BLIND: A set of semantic feature norms from the congenitally blind. Behavior Research Methods 2013;45(4):1218-33. doi:10.3758/s13428-013-0323-4.

[135] Marmor GS. Age at onset of blindness and the development of the semantics of color names. Journal of Experimental Child Psychology 1978;25(2):267-78. URL: http://www. sciencedirect.com/science/article/pii/0022096578900826. doi:10.1016/0022-0965(78)90082-6.

[136] Kim JS, Elli GV, Bedny M. Knowledge of animal appearance among sighted and blind adults. Proceedings of the National Academy of Sciences 2019;116(23):11213-22. URL: https://www.pnas.org/ content/116/23/11213. doi:10.1073/pnas.1900952116.

[137] Lewis M, Zettersten M, Lupyan G. Distributional semantics as a source of visual knowledge. Proceedings of the National Academy of Sciences 2019;116(39):19237-8. URL: https://www. pnas . org/content/116/ 39/19237. doi:10.1073/pnas.1910148116.

[138] Lupyan G, Lewis M. From words-as-mappings to words-as-cues: The role of language in semantic knowledge. Language, Cognition and Neuroscience 2017;34(10):1319-37. URL: https://doi .org/10.1080/ 23273798.2017.1404114. doi:10.1080/23273798.2017.1404114. 
[139] Roebuck H, Lupyan G. The Internal Representations Questionnaire: Measuring modes of thinking. Behavior Research Methods 2020;URL: https://doi.org/10.3758/s13428-020-01354-y. doi:10.3758/s13428-020-01354-y.

[140] Cichy RM, Heinzle J, Haynes JD. Imagery and perception share cortical representations of content and location. Cerebral Cortex 2012;22(2):372-80. doi:10.1093/cercor/bhr106.

[141] Dijkstra N, Bosch SE, van Gerven MA. Vividness of visual imagery depends on the neural overlap with perception in visual areas. The Journal of Neuroscience 2017;37(5):1367-73. doi:10.1523/ JNEUROSCI . 3022-16.2016.

[142] Kosslyn SM. Mental images and the brain. Cognitive Neuropsychology 2005;22(3-4):333-47. doi:10.1080/02643290442000130.

[143] Horikawa T, Kamitani Y. Generic decoding of seen and imagined objects using hierarchical visual features. Nature Communications 2017;8(1):1-15. URL: https://www .nature.com/articles/ ncomms15037. doi:10.1038/ncomms15037.

[144] Dils AT, Boroditsky L. Visual motion aftereffect from understanding motion language. Proceedings of the National Academy of Sciences 2010;107(37):16396-400. URL: https://www.pnas .org/ content/107/37/16396. doi:10.1073/pnas.1009438107.

[145] Maier M, Frömer R, Rost J, Sommer W, Rahman RA. Time course and shared neurocognitive mechanisms of mental imagery and visual perception. bioRxiv 2020;:2020.01.14.905885doi:10.1101/2020. 01.14 .905885 .

[146] Tseng C, Carstensen AB, Regier T, Xu Y. A computational investigation of the Sapir-Whorf hypothesis: The case of spatial relations. In: Papafragou A, editor. Proceedings of the 38th Annual Meeting of the Cognitive Science Society. Austin, TX: Cognitive Science Society; 2016, p. 2231-6. 